\title{
SISTEMA DE ACOMPANHAMENTO DE APRENDIZAGEM
}

\author{
CURITIBA/PR JULHO/2018
}

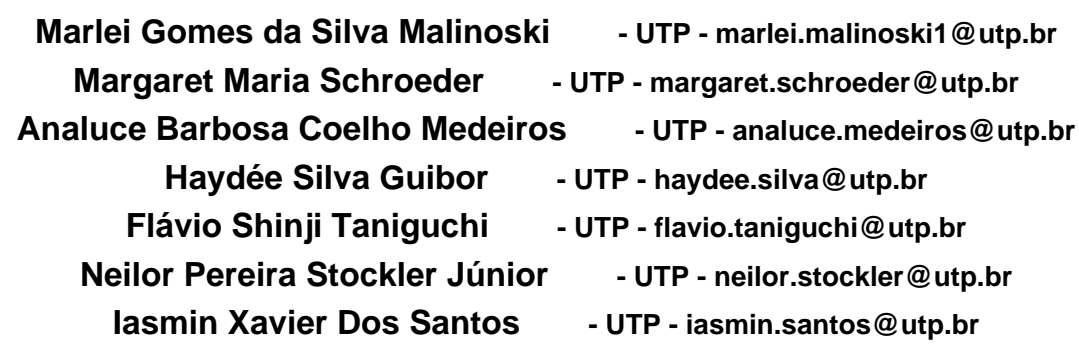

Tipo: Relato de Experiência Inovadora (EI)

Categoria: Métodos e Tecnologias

Setor Educacional: EDUCAÇÃO SUPERIOR

\begin{abstract}
RESUMO
O presente artigo tem por objetivo demonstrar o sistema de acompanhamento de aprendizagem desenvolvido para EAD, em uma Instituição de Ensino Superior, que se baseia no planejamento de aprendizagem por competências. Busca-se analisar a trajetória de aprendizagem do aluno nestas disciplinas a partir do critério quantitativo (nota) e a consequente propositura de ações práticas capazes de ajustar esta trajetória visando ao aprimoramento qualitativo na obtenção individual das competências previstas nos respectivos planos de ensino. $O$ artigo apresenta detalhadamente 0 sistema desenvolvido pela IES, mostrando o olhar pedagógico sobre o sistema gerenciador, o que possibilita vários vieses de análise de acompanhamento da aprendizagem do aluno pelos tutores e professores, bem como a emissão de relatórios para acompanhamento e validações dos resultados. Também mostra a organização das rotinas pedagógicas, a integração do sistema gerenciador ao sistema acadêmico da instituição, viabiliza a preparação das avaliações presenciais e sua integração com o sistema de provas digitais (sistema no qual os alunos realizam digitalmente com ambiente próprio e isolado) e gerencia os agendamentos dos alunos, bem como possibilita a visualização das provas após a realização e integração. Este sistema, pautado tanto no trabalho pedagógico quanto no desenvolvimento tecnológico da equipe multidisciplinar da instituição, assegura um acompanhamento mais qualitativo da aprendizagem do aprendente e favorece a atuação do tutor/professor da educação a distância como um e-moderador.
\end{abstract}

Palavras-chave: e-moderador; gerenciamento; competência.

\section{AGRADECIMENTOS}

À UNIVERSIDADE TUIUTI DO PARANÁ E ÀS TUTORAS GIOVANNA CAROLINA BITTENCOURT DALLAGO E GISELY CRISTINE DE MELO, QUE SEM A MÁXIMA COMPETÊNCIA, QUE SE DEDICAM, O SISTEMA NÃO TERIA SEU ÊXITO. 


\section{1 - Introdução}

O presente artigo tem por objetivo demonstrar o sistema de acompanhamento de aprendizagem desenvolvido para EAD, em uma Instituição de Ensino Superior, baseado no planejamento de aprendizagem por competências. O sistema é resultado do trabalho pedagógico e do desenvolvimento tecnológico da coordenação de educação a distância da Instituição. Mais do que um recurso administrativo, foi pensado como um recurso de suporte para as mediações das ações, sobre a aprendizagem dos alunos. De maneira a qualificar o momento das avaliações, ora digitais, não somente de forma quantitativa, mas também de maneira qualitativa.

O sistema busca minimizar a distância espacial da figura professor e aluno nas avaliações EAD, sistematizando o acompanhamento das competências desenvolvidas, uma vez que gerencia as avaliações e as apropriações feitas e, dessas, quais os alunos obtiveram pouco êxito em seu processo de aprendizagem. A importância da avaliação por competências se fundamenta na mediação pedagógica entre o conteúdo pedido e a forma de avaliação realizada, o que permite identificar o desenvolvimento da aprendizagem. A aprendizagem é, sem dúvida, uma das principais preocupações na Educação a Distância e, junto a ela, a certificação de que o aluno realmente desenvolva as competências necessárias para o aprimoramento de seu projeto de vida. Coll (2010) apresenta a aprendizagem como resultado de uma relação interativa em que há a construção de recursos cognitivos. Como explicitado por (ZABALA e ARNAU, 2010, p. 11)

A competência, no âmbito da educação escolar, deve identi?car o que qualquer pessoa necessita para responder ao problema aos quais será exposta ao longo da vida. Portanto, a competência consistirá na intervenção e?caz nos diferentes âmbitos da vida, mediante ações nas quais se mobilizam, ao mesmo tempo e de maneira interrelacionada, componentes atitudinais, procedimentais e conceituais. (p. 11).

Essas atividades inter-relacionadas devem ser de alguma forma diagnosticadas quanto ao seu êxito na formação de competências, garantindo ao aluno recursos eficazes aos anseios de autonomia e qualificação profissional. Porém a aprendizagem por competências vai além de simplesmente selecionar e responder a um conjunto de questões que mensuram sua obtenção. Aprender por competências requer a apropriação dos recursos expressivos explícitos, ou não, que essa aprendizagem possibilita, sabendo que conforme Zabala e Arnau:

O uso do termo compete?ncia e? uma conseque?ncia da necessidade de superar um 
ensino que, na maioria dos casos, reduziu-se a uma aprendizagem cujo me?todo consiste em memorizac?a?o, isto e?, decorar conhecimentos, fato que acarreta na dificuldade para que os conhecimentos possam ser aplicados na vida. (ZABALA e ARNAU, 2010, p. 17)

Superar a memorização e encontrar a aplicabilidade para o conhecimento mediado no ensino é, sem dúvida, o anseio dos alunos e o desafio dos professores. No ensino a distância, esse fator é evidenciado, pois a aprendizagem está para o engajamento do aluno ao método sugerido e ao desenvolvimento de competências que fomente sua qualificação acadêmica/profissional. Compreendemos como método a proposta pedagógica e todo o design instrucional ofertado para a construção do conhecimento. Compreendemos que a aprendizagem por competências exige como referendado por Gaspar (2004, p.63) in BEHAR (2013 p.24)

A aprendizagem de compete?ncias exige uma atitude construtivista pelo que preve? um percurso com momentos de confronto entre o que ja? existe e o que e? novidade. Obriga a? realizac?a?o continuada de um conjunto de atividades coerentes, a? contratualizac?a?o individual com o aprendente, de forma que este perceba, aceite e valorize a sua diferenc?a, o incremento do trabalho de projeto e o fortalecimento da avaliac?a?o formativa.

Essa contratualização com o aprendente é que impacta todo o processo de aprendizagem EAD, no qual o contato com o aluno é assíncrono, na grande maioria das vezes. A atitude construtiva frente aos momentos de confronto deve ser significada, tanto pelo aluno como pelo professor, nos momentos de aprendizagem, pois não podemos compreender aprendizagem apenas como resultado e sim como processo. Desta forma, nossos objetivos com a proposta integradora de um sistema de gerenciamento e ações pedagógicas são:

\section{2 - Objetivos}

Ao compreendermos a aprendizagem como processo, perceberemos o resultado avaliativo não mais como fim e sim como mediador de uma ação complexa que envolverá atitudes realmente significativas frente à percepção da construção por competências. Desta forma, o objetivo do desenvolvimento de um sistema integrador é gerenciar não somente a nota que o aluno obteve e sim a trajetória de competências que oportunizaram a obtenção da nota descrita. E analisar em que momento, em sua trajetória de aprendizagem, urge ajustes para que o mesmo possa atingir de forma plena a compreensão de todas as competências descritas em seu plano de ensino. Assim, 
delineamos dois objetivos ao aprimorar o sistema de gerenciamento: analisar a trajetória de aprendizagem com base no resultado quantitativo (nota); e ajustar a trajetória de aprendizagem com base na não obtenção de competências explicitadas no Plano de Ensino.

\section{3 - O olhar pedagógico sobre o sistema gerenciador - a trajetória de aprendizagem por competências do aluno}

O sistema de acompanhamento, ora descrito, agrupa todo o gerenciamento de alunos, notas, professores e componentes curriculares. Esta característica o assemelha com os demais sistemas de gerenciamento de alunos, porém esse sistema possibilita vários vieses de análise de acompanhamento da aprendizagem do aluno pelos tutores e professores, bem como possibilita a emissão de relatórios para acompanhamento e validações. Nesse aspecto o sistema de acompanhamento concretiza as ações dos tutores no tocante a estimularem o desenvolvimento de competências pelos alunos, ao verificar entre as competências elegidas na avaliação, quais não obteve êxito.

O sistema é composto por sete ambientes, que serão abaixo apresentados na forma de figuras que ilustram o sistema e sua funcionalidade administrativa e pedagógica. Os ambientes são: Atendimentos; Configurações; Integrações; Pedagógico; POC; Provas Digitais; Relatórios. Os três primeiros ambientes são categorizados como administrativos, porém são fundamentais para análises pedagógicas como será abaixo descrito. O quarto e o quinto são voltados à capacitação e ao acompanhamento de professores e propostas de cursos, dentro do design instrucional institucional. O sexto ambiente é voltado para a gestão das provas digitais e o sétimo ambiente contém os relatórios gerenciais que darão suporte ao pedagógico e ao administrativo em suas respectivas ações.

O sistema está subdividido em sessão administrativa que responde ao objetivo de gerenciamento de alunos e de notas e sessão pedagógica que responde ao objetivo de acompanhar as competências propostas nos planos de ensino e a obtenção de êxito pelos alunos, possibilitando ações mediadoras dos professores. Observe na figura 1

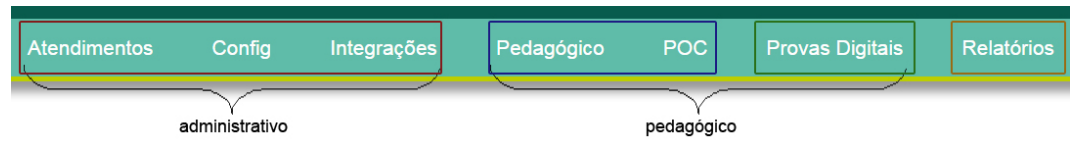

Figura 1: Ambientes administrativos/pedagógicos

\subsection{Ambientes Administrativo - Análises Quantitativas}


O ambiente intitulado Atendimento tem fundamentação inicial, administrativa e possui duas subseções: Atendimentos e Interessados.

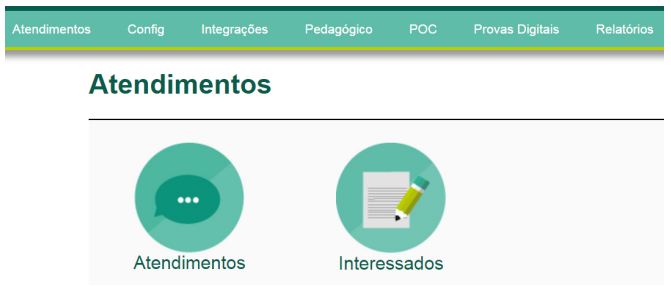

Figura 2: Ambiente Atendimento.

Em Atendimentos, são registradas pelos tutores as dúvidas e sugestões enviadas via email, por telefone ou presencialmente. Cada aluno tem uma área restrita em que suas questões são agrupadas. Desta forma, faz-se um acompanhamento pedagógico das dúvidas individuais e gerais referentes às disciplinas e sobre quais competências versam, bem como são analisadas as sugestões para uma eventual melhoria. Esse acompanhamento favorece ações pontuais na aprendizagem individual, inclusive de redirecionamento de atividades de aprendizagem, uma vez que está no grupo de análise dos tutores. Administrativamente, há o registro de um histórico dos problemas enfrentados pelos alunos no quesito acesso ao sistema, o que favorece também o acompanhamento das matrículas, utilizando a modelagem de um CRM (customer relationship management). $\mathrm{Na}$ subseção Interessados são registradas todas as solicitações de cursos, em suas diversas modalidades e disciplinas, que ainda não são ofertados na instituição. A análise por demanda favorece o desenho de cursos futuros com um perfil imediato de interessados. Ainda de caráter administrativo, o ambiente intitulado Configurações Administrativas possui quatro subseções: Cadastrar Usuários; Cadastrar Períodos; Cadastrar Tipo de Atendimento e Cadastrar Disciplinas.

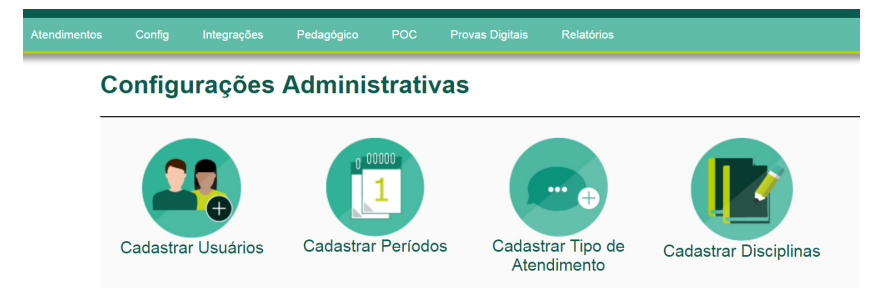

Figura 3: Ambiente Configurações

Este ambiente administrativo organiza as rotinas pedagógicas iniciadas a cada semestre letivo, pois auxilia a organização do número de tutores necessários para atendimento frente ao número de alunos cadastrados por disciplina. Direciona as atividades sugeridas com base no período dos alunos matriculados nas disciplinas e auxilia a ampliação de formas de atendimento, conforme a necessidade imposta. 


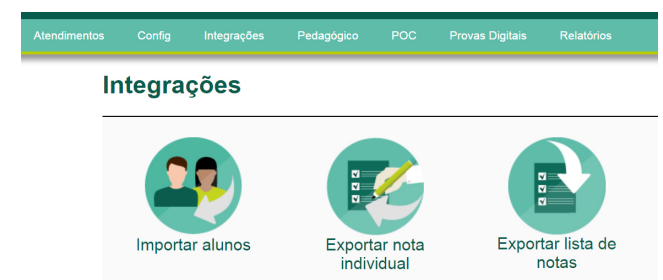

Figura 4: Ambiente Integrações.

O ambiente intitulado Integrações possui três subseções: Importar Alunos; Exportar Nota Individual e Exportar Lista de Notas. Como o nome já enuncia, o ambiente integra o sistema gerenciador ao sistema acadêmico da instituição, possibilitando o acompanhamento e o espelhamento dos resultados.

\subsection{Ambientes Qualitativos de ações sobre a trajetória de aprendizagem}

Em Coll (2017) vemos o termo e-moderador, apresentado por Salmon (2002), que tem o papel de projetista da aprendizagem, tornando-a viável. A quinta fase do modelo de Salmon (2002) refere-se ao desenvolvimento e estabelece ações desejáveis para o emoderador:

promover e desenvolver a reflexão e maximizar o papel da aprendizagem on-line para cada participante e para a experiência de aprendizagem em grupo. Apoiar o processo de reflexão sobre a própria aprendizagem e sobre o curso. (COLL, 2017 p. 128)

Os ambientes Provas Digitais e Relatórios, abaixo descritos, possuem subseções que possibilitam para o tutor e professor atuar como um "e-moderador" frente ao desempenho do aluno. Analisando não somente a nota obtida mas todo o processo de seleção de competências e desempenho do aluno em cada uma delas.

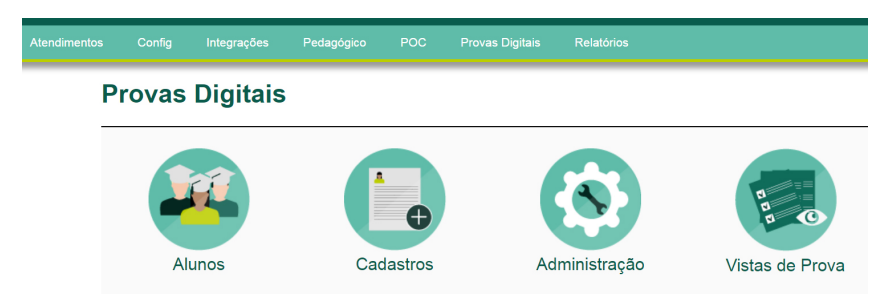

Figura 5: Ambiente Provas Digitais.

Neste ambiente, preparamos as avaliações presenciais dos alunos, integramos com 0 sistema de provas digitais (sistema no qual os alunos realizam digitalmente com ambiente próprio e isolado) e gerenciamos os agendamentos dos alunos, bem como visualizamos sua prova após a realização e integração. Na subseção Alunos podemos 
verificar informações sobre os agendamentos de provas do mesmo, bem como datas de realização e tempo de duração das provas realizadas. A subseção Cadastros é responsável pelas configurações iniciais da prova digital e se desdobra em quatro itens: cadastrar agendamento; cadastrar competências; cadastrar questões e cadastrar provas.

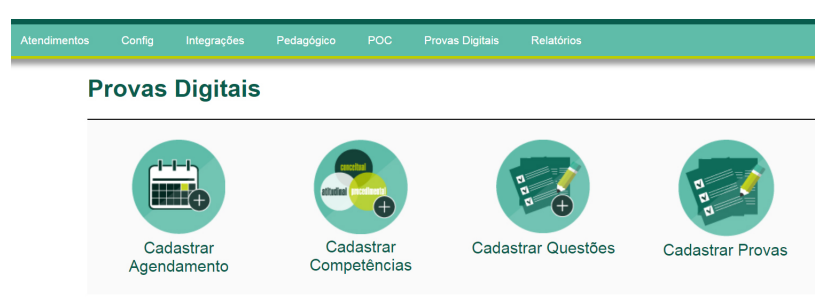

Figura 6: Ambiente Provas Digitais - subseção Cadastros.

A subseção Administração auxilia na logística das provas digitais e realiza a integração com o sistema de provas digitais.

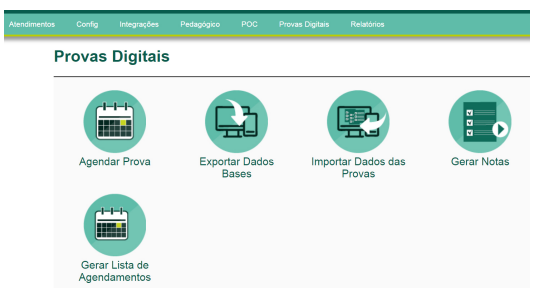

Figura 7: Ambiente Provas Digitais - subseção Administração.

Por último, temos a seção Vistas de Prova, permite ao tutor visualizar a prova realizada pelo aluno e comentada pelo professor, permitindo uma análise da avaliação na presença do aluno, além de um planejamento de ação frente às dificuldades apresentada pelo aluno.

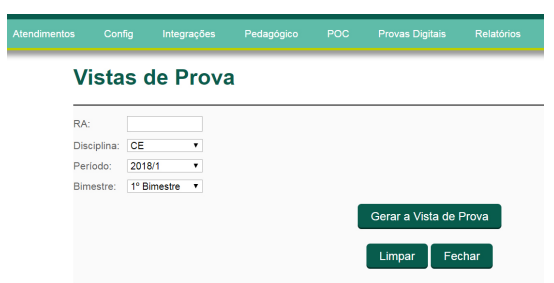

Figura 8: Ambiente Provas Digitais - subseção Vistas de Provas.

O ambiente Relatórios disponibiliza diversas informações que auxiliam nas tomadas de decisões, bem como planejamento de ações da área administrativa e dos tutores. 


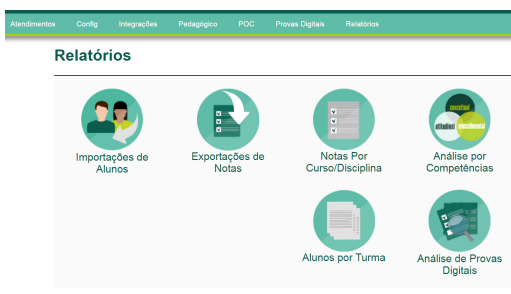

Figura 9: Ambiente Relatórios.

Os dois primeiros relatórios (Importação de Alunos e Exportações de Notas) auxiliam o administrativo a confrontar informações dadas pelos alunos em relação a datas e horas de disponibilização do ambiente virtual de aprendizagem, além do histórico de exportação de notas para o sistema acadêmico. Para os tutores, são disponibilizados quatro relatórios que os auxiliam em ações pedagógicas reativas e preventivas. Através do relatório de Notas por Curso/Disciplina, o tutor pode atuar sobre um determinado grupo de alunos que estejam tendo um desempenho abaixo do esperado em suas avaliações. O relatório de Alunos por Turma permite que o tutor faça um planejamento de acordo com a quantidade de alunos matriculados nas turmas pelas quais é responsável.

Os relatórios de Análise por Competências e de Análise de Provas Digitais auxiliam o tutor a ter uma visão geral dos alunos de sua disciplina e pontual de um determinado aluno. Com estas informações, o tutor pode atuar de diversas formas, como por exemplo, verificar se os alunos de uma determinada disciplina conseguiram desenvolver as competências esperadas e assim melhorar pontualmente o conteúdo da mesma, dando ênfase ou modificando competências em que os alunos não tenham atingido objetivos desejados. Um exemplo de atuação pontual seria o tutor detectar e contatar um determinado aluno que, diferentemente do grupo, não tenha desenvolvido uma determinada competência, podendo atuar sobre sua aprendizagem visando a um desempenho satisfatório, atuando especificamente sobre o problema que o aluno possa estar enfrentando, a fim de evitar até mesmo uma possível evasão.

\section{4 - Análise dos relatórios para ações proativas do e-moderador}

O relatório Notas por Curso/Disciplina possibilita uma análise quantitativa das notas obtidas pelos alunos em uma etapa avaliativa, o que favorece ao setor pedagógico e aos tutores ações de redirecionamento para o curso ou disciplina. O Relatório de Notas é associado ao Relatório de Análise por Competências. 


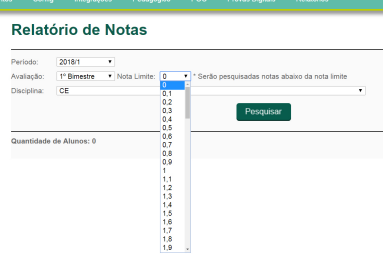

Figura 10: Ambiente Relatórios de Notas.

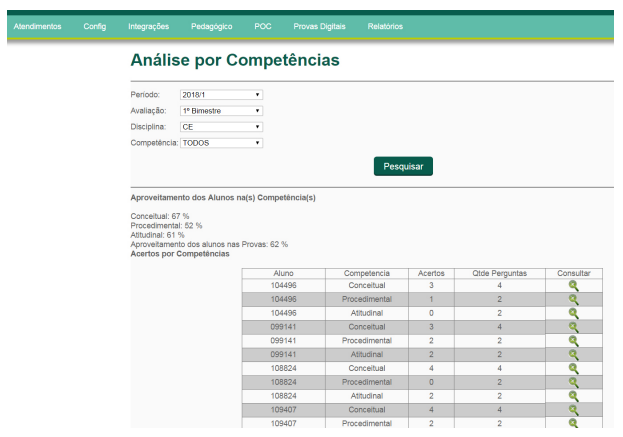

Figura 11: Ambiente Análise por Competências.

A análise por competências permite verificar o aproveitamento dos alunos nos níveis de competências, sejam conceituais, procedimentais ou atitudinais. Inclusive analisar o aproveitamento individual do aluno e em qual competência ele necessita maior atenção por parte dos tutores, favorecendo a compreensão e assimilação do conteúdo. Como apresentado abaixo:

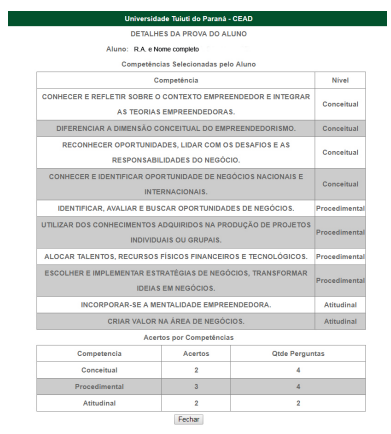

Figura 12: Análise do aproveitamento individual do aluno.

O relatório ainda permite perceber em quais competências houve os maiores números de erros e acertos. Essa análise cruzada permite um redirecionar do curso, possibilitando um acompanhamento mais qualitativo da aprendizagem.

\section{5 - Conclusão}

O sistema de acompanhamento, além de auxiliar nos processos administrativos dos 
alunos nas disciplinas, possibilita mobilidade pedagógica no acompanhamento sistêmico da aprendizagem. Aqui ressaltamos a atuação do "e-moderador" enunciado por Salmon (2002), como vital no processo de aprendizagem desenhado para a educação a distância. A educação é entendida como o processo de interação professor - aluno conteúdo como se observa por COLL, 2010 p. 125, são as atividades frente essa interrelação que produzirão o êxito educacional. Por isso, um sistema que gerencie não só as atividades administrativas acadêmicas e sim consiga inter-relacionar o movimento de aprendizagem em caráter pedagógico produzirá resultados significativos e possibilitará 0 efetivo trabalho de "e-moderador" aqui compreendido como aquele que medeia a aprendizagem levando em consideração sua especificidade e tipo de ensino. Não podemos mais falar de educação a distância como falamos de educação presencial, não é mais o "moderador", que tem como auxílio o convívio e o contexto com o aluno presencial é o "e-moderador" alguém que necessita de recursos tecnológicos para auxiliar a educação mediada por tecnologia e dessa extrair recursos para auxiliar ao aluno na autonomia e competência de ensino.

\section{6 - Referências}

BEHAR, P. A. (org.). Competências em Educação a Distância. Penso, 01/2013. [Minha Biblioteca].

COLL, C. S., MONEREO, C Psicologia da Educação Virtual: aprender e ensinar com as tecnologias da informação e da comunicação. Porto Alegre: Artes Médicas, 2010.

LE BOTERF, G. Construire la Competence Collective de Le?mtreprise. Gestion, v. 22, n. 3, 1997.

PERRENOUd, Ph., GATHER THURLER, M., DE MACEDO, L., MACHADO, N.J. e ALLESSANDRINI, C.D. (2002). As Competências para Ensinar no Século XXI. A Formação dos Professores e o Desafio da Avaliação. Porto Alegre : Artmed Editora, 2002.

SALMON, G. E-moderning. The key to teaching and learning online. London, UK: Kogan Page, 2002.

ZABALA, Antoni; ARNAU, Laia. Como aprender e ensinar competências. Porto Alegre: ArtMed, 2010. 